\title{
Multi-energy calibration applied to atomic spectrometry
}

\author{
Alex Virgilio a , Daniel A. Gonçalves ${ }^{b}$, Tina McSweeney ${ }^{c}$, José A. Gomes Neto ${ }^{d}$, \\ Joaquim A. Nóbrega a , George L. Donati ${ }^{\text {e, }}$ \\ a Group for Applied Instrumental Analysis, Department of Chemistry, Federal University of São Carlos, P. O. Box 676, São Carlos, SP 13565-905, Brazil \\ ${ }^{\mathrm{b}}$ Department of Physics and Chemistry, UNESP-Univ Estadual Paulista, Av. Brasil, 56, Ilha Solteira, SP 15385-000, Brazil \\ ${ }^{c}$ Agilent Technologies, 2500 Regency Parkway, Cary, NC 27518, USA \\ d Department of Analytical Chemistry, UNESP-Univ Estadual Paulista, P.O. Box 355, Araraquara, SP 14800-060, Brazil \\ e Department of Chemistry, Wake Forest University, Salem Hall, Box 7486, Winston-Salem, NC 21709, USA
}

\section{H I G H L I G H T S}

- Calibration using a single standard concentration and several transition energies.

- Only 2 calibration solutions; accuracy comparable with standard additions method.

- Multiple instrument responses and easy identification of spectral interferences.

- Applications with ICP OES, MIP OES and HR-CS FAAS.

- Simple and efficient method for analyzing complex-matrix samples.

\section{A R T I C L E I N F O}

\section{Article history:}

Received 16 March 2017

Received in revised form

16 June 2017

Accepted 21 June 2017

Available online 30 June 2017

\section{Keywords:}

Matrix-matching

Calibration

Multiple analytical signals

Complex-matrix samples

Atomic emission

Atomic absorption

\section{G R A P H I C A L A B S T R A C T}

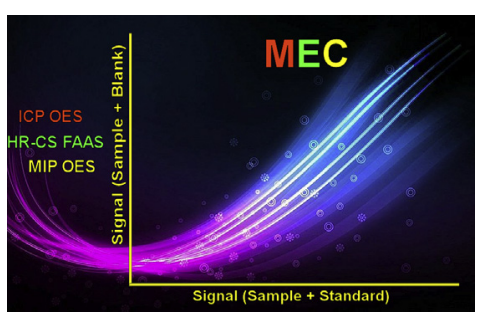

\begin{abstract}
A B S T R A C T
Multi-energy calibration (MEC) is a novel strategy that explores the capacity of several analytes of generating analytical signals at many different wavelengths (transition energies). Contrasting with traditional methods, which employ a fixed transition energy and different analyte concentrations to build a calibration plot, MEC uses a fixed analyte concentration and multiple transition energies for calibration. Only two calibration solutions are required in combination with the MEC method. Solution 1 is composed of $50 \% \mathrm{v} \mathrm{v}^{-1}$ sample and $50 \% \mathrm{v} \mathrm{v}^{-1}$ of a standard solution containing the analytes. Solution 2 has $50 \% \mathrm{v} \mathrm{v}^{-1}$ sample and $50 \% \mathrm{v} \mathrm{v}^{-1}$ blank. Calibration is performed by running each solution separately and monitoring the instrument response at several wavelengths for each analyte. Analytical signals from solutions 1 and 2 are plotted on the $x$-axis and $y$-axis, respectively, and the analyte concentration in the sample is calculated from the slope of the resulting calibration curve. The method has been applied to three different atomic spectrometric techniques (ICP OES, MIP OES and HR-CS FAAS). Six analytes were determined in complex samples (e.g. green tea, cola soft drink, cough medicine, soy sauce, and red wine), and the results were comparable with, and in several cases more accurate than, values obtained using the traditional external calibration, internal standardization, and standard additions methods. MEC is a simple, fast and efficient matrix-matching calibration method. It may be applied to any technique capable of simultaneous or fast sequential monitoring of multiple analytical signals.
\end{abstract}

(c) 2017 Elsevier B.V. All rights reserved.

\footnotetext{
* Corresponding author.

E-mail address: donatigl@wfu.edu (G.L. Donati).
} 


\section{Introduction}

Calibration is an essential component of any quantitative analytical procedure. If an inadequate calibration method is chosen, biased results may be obtained even by using the most sensitive, robust and precise analytical technique available [1]. In most common applications, calibration is performed by recording the analytical signals from a few standard reference solutions and deriving a calibration curve equation correlating instrumental response to analyte concentration. Ideally, the analyte's physicalchemical environment should be the same for standard reference solutions and samples. However, preparing perfectly matrixmatched reference solutions is almost never achievable in practice. The traditional external standard calibration method (EC) is efficient for determinations involving simple matrices. It is applied under the assumption that reference solutions and samples have the same matrix, or that differences in their composition have negligible effects on the analytical signals. Obviously, that is rarely the case, and EC often fails when combined with matrix-sensitive instrumental techniques. The most common alternatives to EC are internal standardization (IS) and standard additions (SA) [2]. The former can improve precision and accuracy if variations in sample transport, sample size, aerosol generation, vaporization, instrument temperature and other physical changes are the main sources of signal bias. However, it usually is ineffective at minimizing matrix effects [2-5]. The method of standard additions is the most recommended approach to complex matrix analyses because calibration solutions and samples are prepared in the same matrix. However, it may be a time consuming method, since a calibration curve with at least three points must be run for each individual sample to ensure accurate results [6-8].

In recent years, novel calibration methods have been proposed to improve accuracy and simplify quantitative analysis. Some of the new methods rely on multivariate calibration and chemometrics [9-11], while others are based on gradient dilution combined with matrix-matching procedures [12-17]. Others still, use traditional calibration methods, but take advantage of the capacity of many modern instruments to simultaneously, or at least fast-sequentially, monitor multiple lines of the same analyte to improve sensitivity, precision and accuracy [18-21]. However, in all cases, the calibration strategy has some component of the traditional relationship instrument response/analyte concentration [2]. A third dimension to this relationship that has rarely been explored for calibration purposes is wavelength, or more broadly, transition energy. In atomic emission spectrometry, for example, instrument response at a certain wavelength $\left(P_{\left(\lambda_{i j}\right)}^{j i}\right)$ is directly related to both analyte concentration $(C)$ and excited-state transition energy $\left(E_{\mathrm{j}}\right)[22]$ :

$I_{\left(\lambda_{i j}\right)}^{j i}=\frac{F C A_{j i} g_{j}}{Q(T)} e^{-E_{j} / k_{B} T}$

where $F=$ instrumental proportionality constant, $A_{j i}=$ transition probability, $g_{j}=$ excited-state degeneracy, $Q(T)=$ partition function, $k_{B}=$ Boltzmann constant, and $T=$ temperature. Traditional calibration curves are built by fixing $E_{j}$ (same wavelength, $\lambda_{\mathrm{ij}}$ ), varying $C$, and adopting $P_{\left(\lambda_{i j}\right)}^{j i}$ as the dependent variable. An alternative approach would be keeping instrument response as the dependent variable $\left(P_{\left(\lambda_{i j}\right)}^{j i}\right.$ in Eq. (1)), but fixing $C$, and varying $E_{j}(i . e$., collecting analytical signals at various wavelengths: $\left.\lambda_{1}-\lambda_{n}\right)$.

In the present work, we describe and validate this alternative method, named multi-energy calibration (MEC). It is combined with a simple matrix-matching procedure to ensure minimal matrix effects, and applied to microwave-induced plasma optical emission spectrometry (MIP OES), inductively coupled plasma optical emission spectrometry (ICP OES), and high-resolution continuum source flame atomic absorption spectrometry (HR-CS FAAS). In the calibration procedure described here, only two calibration solutions are required per sample. Solution 1 is composed of $50 \% \mathrm{v} \mathrm{v}^{-1}$ sample and $50 \% \mathrm{v} \mathrm{v}^{-1}$ of a standard solution containing the analytes. Solution 2 has $50 \% \mathrm{v} \mathrm{v}^{-1}$ sample and $50 \% \mathrm{v} \mathrm{v}^{-1}$ blank. The $1: 1$ proportion is adopted for simplicity. However, as long as the amount of sample is constant in both solutions, other mixture proportions such as 30/70,40/60, etc could also be used. Calibration is performed by running each solution separately and monitoring the instrument response at several wavelengths for each analyte. The mathematical treatment used to determine the analyte concentration in the sample is straightforward. Consider the following relationships:

$I\left(\lambda_{i}\right)^{S a m+S t d}=m\left(C^{S a m}+C^{S t d}\right)$

$I\left(\lambda_{i}\right)^{\text {Sam }}=m C^{\text {Sam }}$

where $I\left(\lambda_{i}\right)^{\text {Sam+Std }}$ and $I\left(\lambda_{i}\right)^{\text {Sam }}$ are the instrument responses at a certain wavelength $(i)$ for solutions 1 and 2, respectively; $m$ is a proportionality constant; and $C^{\text {Sam }}$ and $C^{S t d}$ are the analyte concentrations in the sample and in the standard solution added to solution 1 . In this case, $m$ incorporates everything on the right hand side of Eq. (1), except for $C$. If one considers the same instrumental conditions, and the same matrix since both solutions have $50 \% \mathrm{v}$ $\mathrm{v}^{-1}$ sample, Eqs. (2) and (3) may be combined (Eq. (4)) and rearranged (Eq. (5)):

$$
\begin{aligned}
& \frac{I\left(\lambda_{i}\right)^{\text {Sam }}}{C^{S a m}}=\frac{I\left(\lambda_{i}\right)^{\text {Sam }+ \text { Std }}}{C^{S a m}+C^{S t d}} \\
& I\left(\lambda_{i}\right)^{\text {Sam }}=I\left(\lambda_{i}\right)^{\text {Sam }+S t d}\left[\frac{C^{\text {Sam }}}{C^{S a m}+C^{S t d}}\right]
\end{aligned}
$$

By plotting $I\left(\lambda_{\mathrm{i}}\right)^{\text {Sam }}$ (from solution 2) on the $y$-axis vs. $I\left(\lambda_{\mathrm{i}}\right)^{\text {Sam }+S t d}$ (from Solution 1 ) on the $x$-axis, with instrument responses recorded at several different wavelengths $\left(\lambda_{1}, \lambda_{2}, \lambda_{3}, \ldots, \lambda_{n}\right)$, the slope of that plot's linear regression will be:

$$
\text { Slope }=\left[\frac{C^{\text {Sam }}}{C^{S a m}+C^{S t d}}\right]
$$

Because $C^{S t d}$ is known, the analyte concentration in the sample can then be easily determined by rearranging Eq. (6):

$$
C^{\text {Sam }}=\frac{\text { Slope } C^{\text {Std }}}{(1-\text { Slope })}
$$

To demonstrate its viability and potential for broad application, MEC was used with three different atomic spectrometric techniques (MIP OES, ICP OES and HR-CS FAAS). Six analytes were determined in complex-matrix samples (i.e. green tea, cola soft drink, cough medicine, hard liquor, beer, apple juice, soy sauce, ethanol fuel, vinegar, red wine, and creek water) to evaluate the method's robustness. MEC results were compared with values obtained using the traditional EC, IS and SA methods, and additional validation was carried out by analyzing certified reference materials and spiked samples.

\section{Experimental}

\subsection{Instrumentation}

A MIP OES (4200 MP-AES, Agilent Technologies, Santa Clara, CA, USA), an ICP OES (iCAP 6000 series, Thermo Scientific, Waltham, 
Table 1

Operating conditions used in MIP OES, ICP OES and HR-CS FAAS determinations.

\begin{tabular}{|c|c|c|}
\hline Instrument & Instrumental parameter & Operating condition \\
\hline \multirow[t]{7}{*}{ MIP OES } & Microwave applied power (kW) & 1.0 \\
\hline & Nebulizer gas flow rates $\left(\mathrm{L} \mathrm{min}^{-1}\right)$ & $0.90(\mathrm{Cr}), 0.70(\mathrm{Cu}, \mathrm{Ni})$ \\
\hline & Peristaltic pump speed (rpm) & 15 \\
\hline & Integration time $(\mathrm{s})$ & 3 \\
\hline & Plasma observation position & 0 (all analytes) \\
\hline & Nebulizer & Inert OneNeb \\
\hline & Spray chamber & Cyclonic, double pass \\
\hline \multirow{8}{*}{ ICP OES } & Coolant gas flow rate $\left(\mathrm{L} \mathrm{min}{ }^{-1}\right)$ & 12.0 \\
\hline & Auxiliary gas flow rate $\left(\mathrm{L} \mathrm{min}{ }^{-1}\right)$ & 0.5 \\
\hline & Nebulizer gas flow rate $\left(\mathrm{L} \mathrm{min}^{-1}\right)$ & 0.70 \\
\hline & Peristaltic pump speed (rpm) & 50 \\
\hline & Integration time (s) & 15 \\
\hline & Viewing positioning & Axial \\
\hline & Nebulizer & Concentric \\
\hline & Spray chamber & Cyclonic, single pass \\
\hline \multirow[t]{5}{*}{ HR-CS FAAS } & Acetylene gas flow rates $\left(\mathrm{L} \mathrm{h}^{-1}\right)$ & $50.0(\mathrm{Co}), 60.0(\mathrm{Fe}), 55.0(\mathrm{Ni})$ \\
\hline & Burner height (mm) & 6.0 \\
\hline & Sample aspiration rate $\left(\mathrm{mL} \min ^{-1}\right)$ & 5.0 \\
\hline & Wavelength integrated absorbance (number of pixels) & 3 \\
\hline & Flame type & Air/acetylene \\
\hline
\end{tabular}

MA, USA), and a HR-CS FAAS (ContrAA 300, Analytik Jena, Jena, Germany) were used to evaluate the applicability of the MEC method. Details on each instrument's operating conditions are shown in Table 1.

\subsection{Standard reference solutions, samples and sample preparation}

Distilled-deionized water (18 $\mathrm{M} \Omega \mathrm{cm}$, Milli- ${ }^{\circledR}$, Millipore, Bedford, MA, USA) and trace metal grade nitric acid (Fisher, Pittsburgh, PA, USA) were used to prepare all working solutions. For the samples evaluated in this study, no sample preparation other than simple dilution in $1 \% \mathrm{v} \mathrm{v}^{-1} \mathrm{HNO}_{3}$ was required. Single-element stock solutions containing $1000 \mathrm{mg} \mathrm{L}^{-1}$ of $\mathrm{Co}, \mathrm{Cr}, \mathrm{Cu}, \mathrm{Fe}, \mathrm{Mn}$ or $\mathrm{Ni}$ (SPEX CertPrep, Metuchen, NJ, USA) were used to prepare standard reference solutions and to carry out addition and recovery experiments.

\subsubsection{MIP OES}

All samples were diluted 4 -fold in $1 \% \mathrm{v} \mathrm{v}^{-1} \mathrm{HNO}_{3}$ before analysis, except for tap water (no dilution), and cough medicine (13-fold dilution). Chromium (at 302.1559, 357.8704, 359.3502, 360.5345, 425.4352, 427.4812, 428.9731, 520.4498, 520.8409 and $540.9783 \mathrm{~nm}$ ), Cu (at 216.5093, 217.8944, 324.754, 327.3957, $510.5541,521.8202$ and $578.2132 \mathrm{~nm}$ ), and $\mathrm{Ni}$ (at 232.003, 300.249, $305.082,341.476,343.356,345.847,349.296,352.454$ and $361.939 \mathrm{~nm}$ ) were determined in creek water, green tea, cola soft drink, tap water and cough medicine using MEC. Solution 1 was prepared by mixing $2.5 \mathrm{~mL}$ of $1.0 \mathrm{mg} \mathrm{L}^{-1} \mathrm{Cr}$, Cu and $\mathrm{Ni}$ in $1 \% \mathrm{v} \mathrm{v}^{-1}$ $\mathrm{HNO}_{3}$ with $2.5 \mathrm{~mL}$ of sample. Solution 2 was prepared by mixing $2.5 \mathrm{~mL}$ of sample and $2.5 \mathrm{~mL}$ of $1 \% \mathrm{v} \mathrm{v}^{-1} \mathrm{HNO}_{3}$. For comparison, $\mathrm{Cr}$, $\mathrm{Cu}$ and $\mathrm{Ni}$ were also determined (at 425.433, 324.754, and $341.476 \mathrm{~nm}$, respectively) in spiked samples of cough medicine by EC, IS and SA. Yttrium (371.029 nm) was used as internal standard. Further validation was carried out by addition and recovery experiments with all samples, and by determining these same analytes in certified reference samples, i.e. WPS1-100 (Water Pollution Standard 1, VHG Labs, Manchester, NH, USA), P/N-4400-EP8-100 (Primary Drinking Water Metals, CPI International, Santa Rosa, CA), and DWSS (Drinking Water Secondary Standard, High-Purity Standards, Charleston, SC, USA). The certified reference samples were adequately diluted so analytes would reach a concentration of $0.5 \mathrm{mg} \mathrm{L}^{-1}$.

\subsubsection{ICP OES}

All samples were diluted 5-fold in $1 \% \mathrm{v} \mathrm{v}^{-1} \mathrm{HNO}_{3}$ before analysis. Chromium (at 205.560, 206.550, 266.602, 267.716, 276.654, $283.563,284.325,298.919,318.070,357.869,359.349,360.533$, and $425.435 \mathrm{~nm}$ ), Cu (at 204.379, 211.209, 213.598, 214.987, 217.894, $219.958,221.810,224.700,324.754$, and $327.396 \mathrm{~nm}$ ), and Mn (at $191.510,257.610,259.373,260.569,279.482$, 293.930, 294.920, 348.291, 403.076, and $403.307 \mathrm{~nm}$ ) were determined in cola soft drink, cachaça (Brazilian hard liquor, ca. $40 \% \mathrm{v} \mathrm{v}^{-1}$ ethanol), apple juice, beer, and soy sauce by MEC. Solution 1 was prepared by mixing $12.5 \mathrm{~mL}$ of $1.0 \mathrm{mg} \mathrm{L}^{-1} \mathrm{Cr}, \mathrm{Cu}$ and $\mathrm{Mn}$ in $1 \% \mathrm{v} \mathrm{v}^{-1} \mathrm{HNO}_{3}$ with $12.5 \mathrm{~mL}$ of sample. Solution 2 was prepared by mixing $12.5 \mathrm{~mL}$ of sample and $12.5 \mathrm{~mL}$ of $1 \% \mathrm{v} \mathrm{v}^{-1} \mathrm{HNO}_{3}$. For comparison, $\mathrm{Cr}, \mathrm{Cu}$ and Mn were also determined (at 357.869, 327.396 and $257.610 \mathrm{~nm}$, respectively) in all samples by EC, IS and SA. Yttrium (371.0287 nm) was used as internal standard.

\subsubsection{HR-CS FAAS}

All samples were diluted 5-fold in $1 \% \mathrm{v} \mathrm{v}^{-1} \mathrm{HNO}_{3}$ before analysis. Cobalt (at 217.4600, 230.9010, 240.7254, 241.1620, 241.4460, $241.5290,242.4930,243.5823,243.6660,243.9040,252.1363$, 252.8970, 253.5960, 304.4000, and $345.3510 \mathrm{~nm}$ ), Fe (at 216.6770, $247.2900,247.9780,248.3270,248.8143,249.0640,249.1160$, $252.2850,252.7435,271.9030,296.6900, \quad 302.0639$, and $302.1073 \mathrm{~nm}$ ), and $\mathrm{Ni}$ (at 231.0960, 231.2340, 231.3660, 231.7170, 232.0030, 232.5800, 234.5540, 300.2490, 305.0816, 310.1560, 341.4770 , and $352.4536 \mathrm{~nm}$ ) were determined in ethanol fuel, vinegar, and red wine by MEC. Solution 1 was prepared by mixing $25.0 \mathrm{~mL}$ of $1.0 \mathrm{mg} \mathrm{L}^{-1} \mathrm{Co}$, Fe and $\mathrm{Ni}$ in $1 \% \mathrm{v} \mathrm{v}^{-1} \mathrm{HNO}_{3}$ with $25.0 \mathrm{~mL}$ of sample. Solution 2 was prepared by mixing $25.0 \mathrm{~mL}$ of sample and $25.0 \mathrm{~mL}$ of $1 \% \mathrm{v} \mathrm{v}^{-1} \mathrm{HNO}_{3}$. For comparison, $\mathrm{Co}$, Fe and $\mathrm{Ni}$ were also determined (at 240.7254, 248.3270, $232.0030 \mathrm{~nm}$, respectively) in all samples by EC, IS and SA. Rhodium (343.4890 nm) was used as internal standard.

\section{Results and discussion}

\subsection{MEC strategy}

Figs. 1 and 2 show typical MEC plots, which are based on Eq. (5). In Fig. 1, ten $\mathrm{Cr}$ emission lines between 302.1559 and $540.9783 \mathrm{~nm}$ were monitored by MIP OES, and the analyte concentration in a 


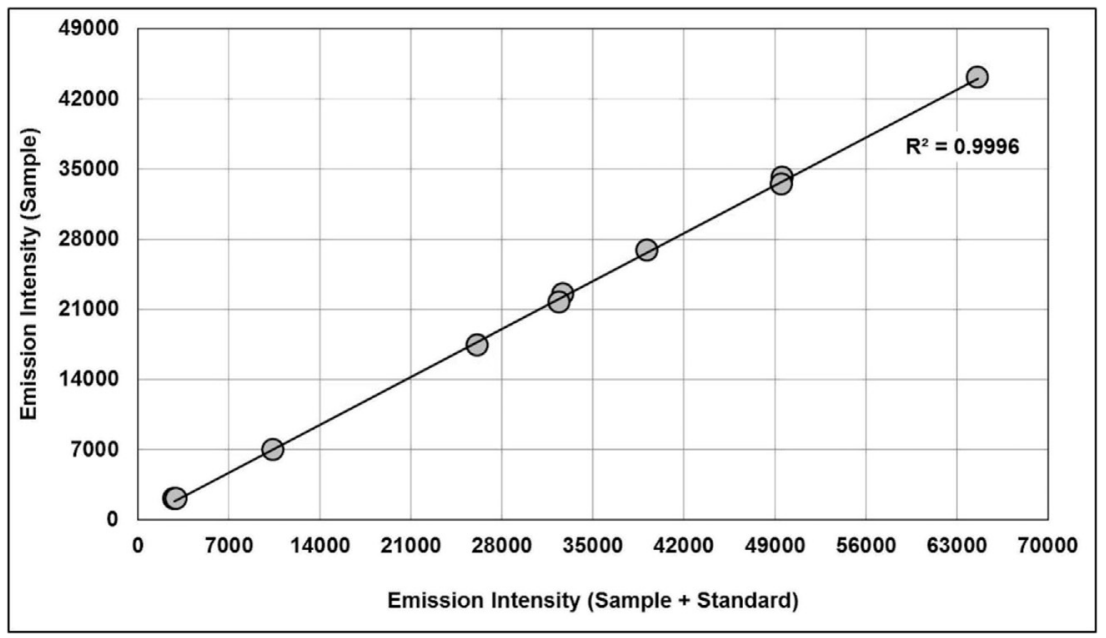

Fig. 1. Multi-energy calibration plot used to determine Cr in Water Pollution Standard 1 (WPS1-100, VHG Labs) by MIP OES.

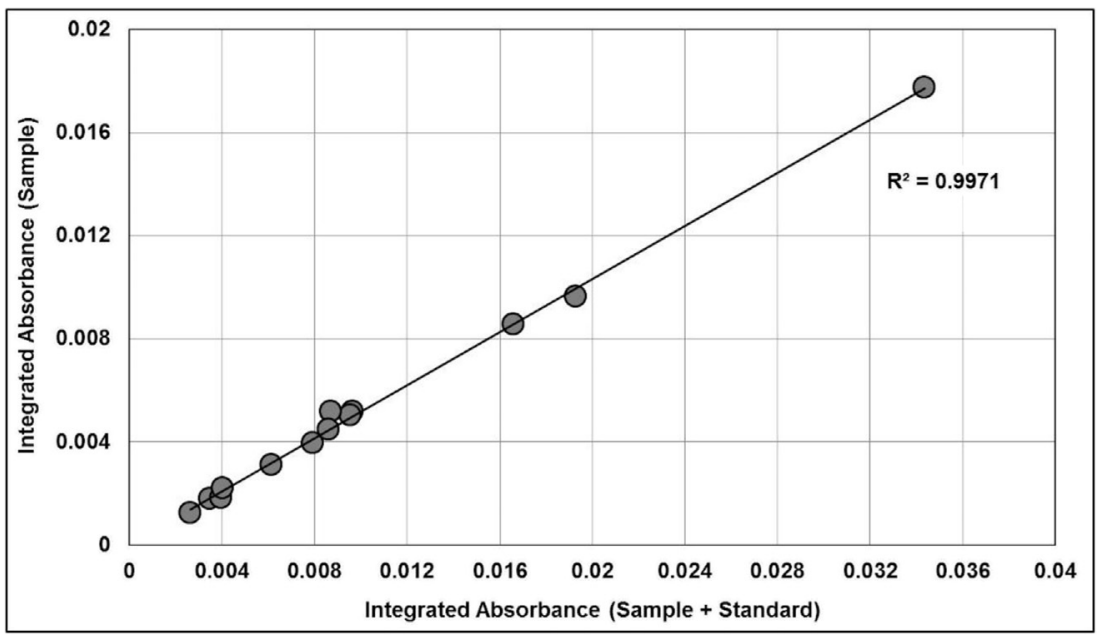

Fig. 2. Multi-energy calibration plot used to determine Fe in red wine by HR-CS FAAS.

certified reference sample of water (WPS1-100) was accurately determined using Eq. (7). Fig. 2 shows a MEC plot built from thirteen Fe absorption lines in the $216.6770-302.1073 \mathrm{~nm}$ range. In this case, Fe was accurately determined in red wine by HR-CS FAAS.

The theoretical basis of the MEC method is demonstrated by calculations involving signal intensities determined from fundamental constants (see Supplementary Material). In the present study, we have chosen as many analytical wavelengths as possible considering both the number of sufficiently sensitive lines available per analyte, and the expected improvement in accuracy and precision as more calibration points (i.e. analytical lines) are used $[18,23]$. In addition to its matrix-matching capabilities, one of the main advantages of using MEC is the possibility of readily identifying potential interferences on specific analytical lines. Matrix effects, or more likely in this case spectral interference, can disproportionally affect the analytical signal at a certain wavelength for solution 1 (sample + standard) and solution 2 (sample + blank). In MEC, the calibration point specific to that wavelength will appear outside the calibration curve linear range, and could easily be discarded. Such simple and direct way of identifying spectral interferences is not possible with single-wavelength calibration methods. By applying the traditional EC, for example, one could identify the problem only after $(i)$ running a reference sample and a multi-solution calibration curve, (ii) monitoring the analytical signal at different wavelengths, and (iii) comparing the results with expected values.

On the other hand, MEC is more prone to systematic errors associated with solution preparation. Inaccurate results will be obtained if the reference standard added to solution 1 has the wrong concentration. In a traditional one-wavelength, multi-solution calibration method, such systematic error would be easily identified as an outlier point in the calibration curve linear range. Another potential limitation of the MEC method is that it can only work for analytes presenting multiple analytical lines. However, considering modern instrumental techniques capable of simultaneous or fast sequential multi-wavelength determinations, this may be a minor limitation, especially for elements such as the transition metals [18-21]. It is also important to note that, similar to the SA method, additive interferences such as background correction errors will not be adequately corrected in MEC.

With the traditional calibration methods, one can determine if and how much an unknown sample needs to be diluted only after comparing its analytical signal with that recorded for a reference solution. The 50:50 ratio adopted in this study (i.e. both calibration 
solutions contain $50 \% \mathrm{v} \mathrm{v}^{-1}$ of sample) may be the most straightforward approach for MEC because it assumes neither a too high nor a too low analyte concentration. Typical total dissolved solids content and its effect on instrumental method performance can also be used as a criterion for deciding the dilution factor.

Another important parameter, which is also closely related to the sample dilution factor, is the concentration of the standard added to solution 1. Preliminary experiments (not shown) indicate that the best results are achieved when the solution $1 /$ solution 2 analytical signal ratio at any given wavelength is $\geq 1.2$. Therefore, the best strategy to analyze an unknown sample by MEC using the analytical techniques described in this study is to employ an intermediary standard concentration (e.g. $1.0 \mathrm{mg} \mathrm{L}^{-1}$ ) and monitor as many analytical lines as possible, but only use those for which the analytical signal from solution 1 is at least $20 \%$ higher than that recorded for solution 2 .

\subsection{Limits of detection, accuracy and precision}

The limits of detection (LOD) for determinations using MEC were calculated according to IUPAC's recommendations as 3 times the blank equivalent concentration $\left(C_{B}\right)$ : $L O D=3 C_{B} . A 1 \% v^{-1}$ $\mathrm{HNO}_{3}$ solution (i.e. blank) was used as sample, and $\mathrm{C}_{B}$ was calculated using MEC $(\mathrm{n}=10)$. For MIP OES, the LODs for $\mathrm{Cr}$ (10 emission lines), $\mathrm{Cu}$ (7 emission lines) and $\mathrm{Ni}$ (9 emission lines) were 1, 2 and $30 \mu \mathrm{g} \mathrm{L}^{-1}$, respectively. For ICP OES, the LODs for $\mathrm{Cr}$ (13 emission lines), $\mathrm{Cu}$ (10 emission lines) and $\mathrm{Mn}$ (10 emission lines) were 1, 0.7 and $0.8 \mu \mathrm{g} \mathrm{L}^{-1}$, respectively. For HR-CS FAAS, the calculated values were 8,30 and $9 \mu \mathrm{g} \mathrm{L}^{-1}$ for Co (15 absorption lines), Fe (14 absorption lines) and $\mathrm{Ni}$ (12 absorption lines), respectively. These values are comparable with typical LODs reported for each of the instruments used [24-26].

The accuracy of the MEC method was evaluated by analyzing certified reference samples and by addition/recovery tests. Adequate recoveries were obtained for all analytes, although

Table 2

Determination of $\mathrm{Cr}$, $\mathrm{Cu}$ and $\mathrm{Ni}$ in certified reference samples by MIP OES and MEC. Results are the mean \pm 1 standard deviation $(n=3)$. The reference concentration for all analytes and samples is $100 \mathrm{mg} \mathrm{L}^{-1}$.

\begin{tabular}{lll}
\hline Sample & Analyte & Found $\left(\mathrm{mg} \mathrm{L}^{-1}\right)$ \\
\hline WPS1-100 & $\mathrm{Cr}$ & $98.1 \pm 0.4$ \\
& $\mathrm{Cu}$ & $91.6 \pm 1.1$ \\
& $\mathrm{Ni}$ & $87.9 \pm 0.9$ \\
$\mathrm{P} / \mathrm{N}-4400-\mathrm{EP} 8-100^{\mathrm{b}}$ & $\mathrm{Cr}$ & $101.8 \pm 0.1$ \\
$\mathrm{DWSS}^{\mathrm{c}}$ & $\mathrm{Cu}$ & $92.2 \pm 0.2$ \\
\hline${ }^{\mathrm{a}}$ Water Pollution Standard 1 (VHG Labs, Manchester, NH). \\
${ }^{\mathrm{b}}$ Primary Drinking Water Metals (CPI International, Santa Rosa, CA). \\
${ }^{\mathrm{c}}$ Drinking Water Secondary Standard (High-Purity Standards, Charleston, SC).
\end{tabular}

slightly low for Ni determination in WPS1-100 (Table 2). Table 3 shows the results for the addition/recovery tests. As it can be seen, MEC is comparable with EC, IS and SA, presenting recoveries between $94.4 \%$ ( $\mathrm{Ni}$ by MIP OES) and $106.6 \%$ ( $\mathrm{Cr}$ by MIP OES). Additional experiments were carried out with creek water, green tea, cola soft drink, tap water, cachaça, beer, soy sauce, ethanol fuel, and red wine. MEC recoveries for a $0.500 \mathrm{mg} \mathrm{L}^{-1}$ spike were all between $90.8 \%$ ( $\mathrm{Cr}$ in tap water by MIP OES) and $108.4 \%$ (Fe in red wine by HR-CS FAAS). For these same samples, EC, IS and SA recoveries were in the $35.9-113 \%, 51.8-116.5 \%$, and $73.2-119.7 \%$ ranges, respectively. As expected, the matrix-matching capabilities of MEC and SA can minimize matrix effects, which leads to generally more accurate results when compared with EC and IS.

Because MEC is a matrix-matching strategy with characteristics similar to SA, less precise results should be expected when compared with EC. Additional experiments are needed to evaluate MEC's precision in more detail. However, considering the standard deviation values shown in Table 3, one may conclude that MEC's precision is at least comparable with EC. As discussed before, these adequate precisions may stem from using several calibration points (i.e. analytical lines) with the MEC method $[18,23]$.

\subsection{Application to complex-matrix samples}

The robustness of the MEC method was evaluated by analyzing complex-matrix samples. For creek water, green tea, cola soft drink, and tap water analyzed by MIP OES, Cu concentrations were $0.240 \pm 0.004, \quad 0.407 \pm 0.003, \quad 0.345 \pm 0.002$, and $0.180 \pm 0.002 \mathrm{mg} \mathrm{L}^{-1}$, respectively. Chromium and $\mathrm{Ni}$ values in these samples were all lower than the respective LODs. Cola soft drink, cachaça, beer, apple juice and soy sauce were analyzed by ICP OES. The results for $\mathrm{Cr}$ were between $0.074 \pm 0.004 \mathrm{mg} \mathrm{L}^{-1}$ (beer) and $0.098 \pm 0.006 \mathrm{mg} \mathrm{L}^{-1}$ (soy sauce). Values between $0.028 \pm 0.001 \mathrm{mg} \mathrm{L}^{-1}$ (cola soft drink) and $0.202 \pm 0.008 \mathrm{mg} \mathrm{L}^{-1}$ (cachaça) were found for $\mathrm{Cu}$. Manganese concentrations in cola soft drink and cachaça were below the LOD. For beer, apple juice and soy sauce, the values found were $0.052 \pm 0.004,0.098 \pm 0.006$, and $0.102 \pm 0.006 \mathrm{mg} \mathrm{L}^{-1}$, respectively. HR-CS FAAS results were as follows: Co $<$ LOD in all samples; $\mathrm{Fe}=0.520 \pm 0.040 \mathrm{mg} \mathrm{L}^{-1}$ in red wine, and $<$ LOD in ethanol fuel; $\mathrm{Ni}=0.045 \pm 0.001 \mathrm{mg} \mathrm{L}^{-1}$ in ethanol fuel, and $<$ LOD in red wine.

\section{Conclusions}

MEC is a simple and efficient alternative to the traditional calibration methods. Due to its matrix-matching capabilities, accurate and precise results are obtained using only two calibration solutions, which also contributes to superior sample throughput when compared with SA (the SA method usually requires more than two

Table 3

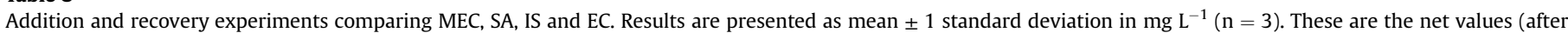

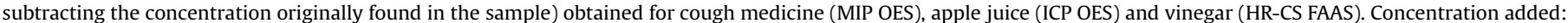
$0.500 \mathrm{mg} \mathrm{L}^{-1}$.

\begin{tabular}{|c|c|c|c|c|c|}
\hline \multirow[t]{2}{*}{ Method } & \multirow[t]{2}{*}{ Analyte } & \multicolumn{4}{|l|}{ Found $\left(\mathrm{mg} \mathrm{L}^{-1}\right)$} \\
\hline & & MEC & SA & IS & $\mathrm{EC}$ \\
\hline \multirow[t]{3}{*}{ MIP OES } & $\mathrm{Cr}$ & $0.533 \pm 0.003$ & $0.513 \pm 0.003$ & $0.498 \pm 0.002$ & $0.478 \pm 0.001$ \\
\hline & $\mathrm{Cu}$ & $0.517 \pm 0.002$ & $0.540 \pm 0.020$ & $0.510 \pm 0.010$ & $0.490 \pm 0.010$ \\
\hline & $\mathrm{Ni}$ & $0.472 \pm 0.005$ & $0.529 \pm 0.008$ & $0.499 \pm 0.006$ & $0.481 \pm 0.003$ \\
\hline \multirow[t]{3}{*}{ ICP OES } & $\mathrm{Cr}$ & $0.505 \pm 0.002$ & $0.477 \pm 0.003$ & $0.568 \pm 0.001$ & $0.472 \pm 0.001$ \\
\hline & $\mathrm{Cu}$ & $0.520 \pm 0.002$ & $0.475 \pm 0.003$ & $0.538 \pm 0.001$ & $0.444 \pm 0.001$ \\
\hline & $\mathrm{Mn}$ & $0.519 \pm 0.003$ & $0.462 \pm 0.003$ & $0.441 \pm 0.001$ & $0.383 \pm 0.001$ \\
\hline \multirow[t]{3}{*}{ HR-CS FAAS } & Co & $0.529 \pm 0.009$ & $0.600 \pm 0.007$ & $0.489 \pm 0.004$ & $0.491 \pm 0.004$ \\
\hline & $\mathrm{Fe}$ & $0.487 \pm 0.004$ & $0.589 \pm 0.012$ & $0.506 \pm 0.017$ & $0.508 \pm 0.016$ \\
\hline & $\mathrm{Ni}$ & $0.527 \pm 0.005$ & $0.620 \pm 0.005$ & $0.535 \pm 0.003$ & $0.536 \pm 0.003$ \\
\hline
\end{tabular}


calibration solutions to better define a relationship between analyte concentration and instrument response). MEC's main limitation is the requirement for at least three analytical lines per element. Although not systematically evaluated in this proof-ofconcept study, more accurate and precise results are expected as more analytical lines (i.e. calibration points) are used. On the other hand, spectral interferences are more easily detected with this method, as outlier calibration points are readily identified. This is an advantage exclusive to MEC, which is not available in traditional one-wavelength calibration methods.

As shown in the present study, MEC requires no instrument modifications or special strategies for application in widely used techniques such as atomic absorption and atomic emission spectrometry. Data processing is straightforward and may easily be incorporated in the instrument-controlling software for automatic calculation of analyte concentrations. Provided MEC's basic conditions are met, it may also be used in other techniques, e.g. quantitative analysis involving molecular spectroscopy.

\section{Acknowledgments}

The authors would like to thank Agilent Technologies, Thermo Scientific - Analitica, and the Department of Chemistry at Wake Forest University for their support to this work. The fellowships provided to A.V. (Grant 2014/18393-1) by the São Paulo Research Foundation (FAPESP, Brazil), and to D.A.G. by the Coordenação de Aperfeiçoamento de Pessoal de Nível Superior (CAPES, Brazil, Grant 99999.002566/2014-01) are also greatly appreciated. J.A.N. (Grant 303107/2013-8) and J.A.G.N (Grant 303255/2013-7) are also thankful to the Conselho Nacional de Desenvolvimento Cientifico e Tecnológico (CNPq) for their researchships.

\section{Appendix A. Supplementary data}

Supplementary data related to this article can be found at http:// dx.doi.org/10.1016/j.aca.2017.06.040.

\section{References}

[1] H. Mark, Principles and practice of spectroscopic calibration, in: J.D. Winefordner, I.M. Kolthoff (Eds.), Chemical Analysis: a Series of Monographs on Analytical Chemistry and its Applications, first ed. vol. 118, WileyInterscience, New York, 1991, 192pp.

[2] P. Koscielniak, M. Wieczorek, Univariate analytical calibration methods and procedures: a review, Anal. Chim. Acta 944 (2016) 14-28.

[3] V. Thomsen, Walther Gerlach and the foundations of modern spectrochemical analysis, Spectroscopy 17 (2002) 117-120.

[4] H. Veening, Quantitative infrared analysis of xylene mixtures: internal standard method, J. Chem. Educ. 43 (1966) 319-320.

[5] M.A. Bechlin, F.M. Fortunato, E.C. Ferreira, J.A. Gomes Neto, J.A. Nóbrega, G.L. Donati, B.T. Jones, Bismuth as a general internal standard for lead in atomic absorption spectrometry, Anal. Chim. Acta 831 (2014) 24-30.

[6] W.R. Kelly, K.W. Pratt, W.F. Guthrie, K.R. Martin, Origin and early history of Die
Methode des Eichzusatzes or the Method of Standard Addition with primary emphasis on its origin, early design, dissemination, and usage of terms, Anal. Bioanal. Chem. 400 (2011) 1805-1812.

[7] M.J. Bader, A systematic approach to standard addition methods in instrumental analysis, J. Chem. Educ. 57 (1980) 703-706.

[8] D.J. Harvey, External standards or standard addition? Selecting and validating a method of standardization, J. Chem. Educ. 79 (2002) 613-615.

[9] J.M. Andrade, M.J. Cal-Prieto, M.P. Gómez-Carracedo, A. Carlosena, D. Prada, A tutorial on multivariate calibration in atomic spectrometry techniques, J. Anal. At. Spectrom. 23 (2008) 15-28.

[10] T.M. Zhang, B. Yuan, Y.A. Liang, J. Cao, C.X. Pan, B. Ying, D.Y. Lu, Elimination of matrix effect and simultaneous determination of multi-components in complex systems by matrix coefficient non-linearity multivariate calibration based on single point response signals, Anal. Sci. 23 (2007) 581-587.

[11] H.W. Lee, A. Bawn, S. Yoon, Reproducibility, complementary measure of predictability for robustness improvement of multivariate calibration models via variable selections, Anal. Chim. Acta 757 (2012) 11-18.

[12] F.M. Fortunato, M.A. Bechlin, J.A. Gomes Neto, G.L. Donati, B.T. Jones, Interna standard addition calibration: determination of calcium and magnesium by atomic absorption spectrometry, Microchem. J. 122 (2015) 63-69.

[13] W.B. Jones, G.L. Donati, C.P. Calloway Jr., B.T. Jones, Standard dilution analysis, Anal. Chem. 87 (2015) 2321-2327.

[14] D.A. Goncalves, T. McSweeney, M.C. Santos, B.T. Jones, G.L. Donati, Standard dilution analysis of beverages by microwave-induced plasma optical emission spectrometry, Anal. Chim. Acta 909 (2016) 24-29.

[15] A. Virgilio, D. Schiavo, L.C. Costa, J.A. Nóbrega, B.T. Jones, G.L. Donati, Inductively coupled plasma mass spectrometry and standard dilution analysis applied to concentrated acids, Talanta 161 (2016) 826-829.

[16] Y. Cheung, A.J. Schwartz, G.M. Hieftje, Use of gradient dilution to flag and overcome matrix interferences in axial-viewing inductively coupled plasmaatomic emission spectrometry, Spectrochim. Acta, Part B 100 (2014) 38-43.

[17] Y. Cheung, S.J. Ray, A.J. Schwartz, G.M. Hieftje, Use of gradient dilution to detect and correct matrix interferences in inductively coupled plasma-timeof-flight mass spectrometry (ICP-TOFMS), Appl. Spectrosc. 70 (2016) 1797-1805.

[18] R. Kucharkowski, D. Jankova, E. Herrmann, A. John, Contributions to accuracy improvement of simultaneous ICP atomic emission spectrometry using multiline measurements of analyte and internal standard elements: applications for the analysis of permalloy, Fresenius J. Anal. Chem. 361 (1998) 532-539.

[19] J.M. Mermet, Is it still possible, necessary and beneficial to perform research in ICP-atomic emission spectrometry? J. Anal. At. Spectrom. 20 (2005) 11-16.

[20] D. Schiavo, L.C. Trevizan, E.R. Pereira-Filho, J.A. Nóbrega, Evaluation of the use of multiple lines for determination of metals in water by inductively coupled plasma optical emission spectrometry with axial viewing, Spectrochim. Acta, Part B 64 (2009) 544-548.

[21] G.L. Donati, M.H. Gonzales, J.A. Nóbrega, B.T. Jones, Multi-wavelength determination of cobalt by tungsten coil atomic emission spectrometry, Anal. Lett. 43 (2010) 1723-1733.

[22] E. Tognoni, M. Hidalgo, A. Canals, G. Cristoforetti, S. Legnaioli, A. Salvetti, V. Palleschi, Combination of the ionic-to-atomic line intensity ratios from two test elements for the diagnostic of plasma temperature and electron number density in inductively coupled plasma atomic emission spectroscopy, Spectrochim. Acta. Part B 62 (2007) 435-443.

[23] J.C. Miller, J.N. Miller, Statistics for Analytical Chemistry, first ed., John Wiley and Sons, Chichester, 1984, pp. 82-118.

[24] G.L. Donati, R.S. Amais, D. Schiavo, J.A. Nóbrega, Determination of Cr, Ni, Pb and $\mathrm{V}$ in gasoline and ethanol fuel by microwave plasma optical emission spectrometry, J. Anal. At. Spectrom. 28 (2013) 755-759.

[25] Thermo Scientific iCAP 6000 Series ICP: Instrument Detection Limits. Available at https://static.thermoscientific.com/images/D10699 .pdf. Accessed on January 9, 2017.

[26] B. Welz, H. Becker-Ross, S. Florek, U. Heitmann, High-resolution Continuum Source AAS: the Better Way to Do Atomic Absorption Spectrometry, first ed., Wiley-VCH, Weinheim, 2005, p. 69. 